\title{
Comparison of 12 different containers for dispensing anti-inflammatory drugs
}

\author{
P LE GALLEZ, H A BIRD, V WRIGHT, A P BENNETT
}

\begin{abstract}
Twelve containers manufactured by 10 pharmaceutical companies for dispensing anti-inflammatory drugs, 10 of which are currently in use in the United Kingdom, have been compared in 99 patients with arthritis of the hands. Patients were given the containers in random order and were asked to open them, extract the tablets, and close them. Patients were questioned on ease of handling at each stage and were then timed on reopening and closing each container. Finally, the patients were asked which container was the best and which was the worst. There was a wide variation in popularity of containers. One was judged outstanding on almost every attribute, and four were preferred over the others on most attributes. A successful container for arthritic hands is likely to have a sharply angulated or "wing" cap placed on a tall slim base that is also angulated. Flip off tops, tops with long threads requiring many turns, very small containers, and glass were regarded as unfavourable.
\end{abstract}

Manufacturers should take note of these findings and, where necessary, consider redesigning the containers.

\section{Introduction}

A wide variety of non-steroidal anti-inflammatory agents are currently available for the treatment of rheumatic diseases in the United Kingdom, and there is an almost equal variety in design of the containers in which these preparations are dispensed. Previous studies have shown that patients with rheumatoid arthritis find difficulty extracting tablets from blister packs ${ }^{1}$ and that patients attending a regional centre for rheumatic diseases had difficulty in opening at least half of a series of bottles available in $1976 .{ }^{2}$ Since that time there has been more variation in design of containers, with the introduction of "flip off" tops and "wing" tops. Attention has already been directed to the fact that childproof screw packs can often not be opened by patients with arthritis. ${ }^{3}$

Clinical Pharmacology Unit, Royal Bath Hospital, Harrogate, and Rheumatism Research Unit, University Department of Medicine, General Infirmary at Leeds

P LE GALLEZ, SRN, clinical metrologist

H A BIRD, MD, MRCP, lecturer in rheumatology and honorary consultant rheumatologist

V WRIGHT, MD, FRCP, professor of rheumatology

Cassenne Limited, Roussel House, Wembley, Middlesex HA9 ONF A P BENNETT, BSC, group product manager

Correspondence to: Dr H A Bird, Clinical Pharmacology Unit, Royal Bath Hospital, Cornwall Road, Harrogate, North Yorkshire HG1 2PS.
With the plethora of new drugs available for the treatment of rheumatic diseases we felt that the time had come to re-evaluate the design of containers. We selected 10 containers from the existing diverse range; these represented the manufacturers' packs most likely to be dispensed against a prescription for 10 common anti-inflammatory agents. We also included two new designs not then available to pharmacists. The containers were evaluated in a group of 99 consecutive patients (outpatients or inpatients) with arthritis of the hands.

\section{Patients and methods}

A total of 99 patients (14 men, 85 women) with arthritis affecting the hands were studied. We recorded data on age, sex, principal rheumatic diagnosis, duration of disease, duration of arthritis affecting the hand, how often the patient took medication each day, which was the dominant hand, and whether the patients opened their own medicine containers. An attempt to quantify the degree of impairment to the hand was made by recording grip strength (mean of three readings from each hand) and assessing degree of arthritis as none, mild, moderate, or severe on each side at the hand, wrist, elbow, and shoulder.

Each patient was given each of the 12 containers (fig 1) in an order assigned at random. Containers were closed and contained the tablets normally provided by the manufacturer in that container. The sealing strips of "flip top" containers that would have needed breaking on the first opening were removed before presentation. Table I shows details of the 12 containers. A careful explanation was given to each patient to ensure that they understood what was required.

Patients were invited to open each container and to state, firstly, whether it was very easy, easy, difficult, very difficult, or impossible to open, and, secondly, whether pain was encountered. They then took two tablets from the container and reclosed it. After each of these steps these same two questions were asked. Patients then defined the size of the body, shape of the body, size of the closure, and shape of the closure as good or bad. They also stated whether their

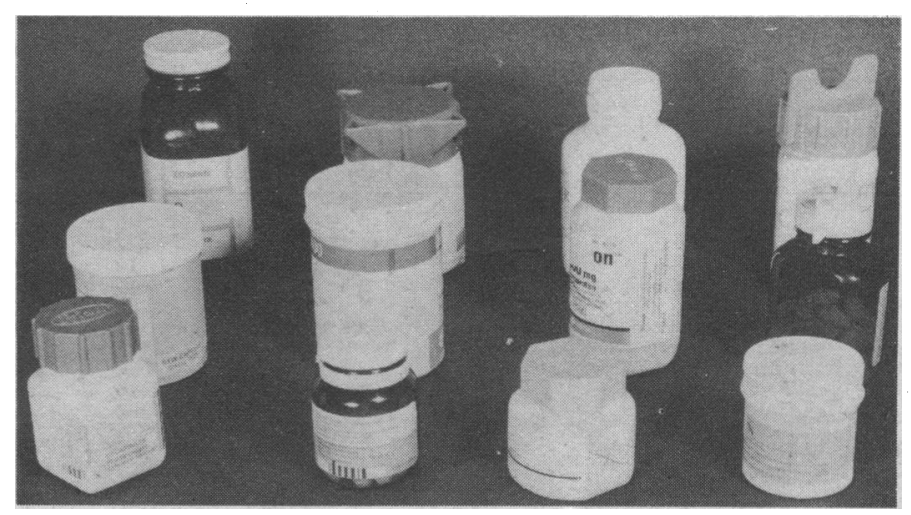

FIG 1 -The 12 containers tested. Table I gives further details of containers. 
overall opinion of the container was good or bad and whether they had ever handled the container before. Patients next reopened the container, removed two tablets (usually into their hand), and reclosed the container; this procedure was timed and was repeated for each container in random order. At the end patients were asked which container was the best and which was the worst.

\section{Results}

The ages of the 99 patients ( 14 men, 85 women) range from 21 to $>70$, with 49 aged 61 or over. Eleven had osteoarthritis, 81 rheumatoid arthritis, and 10 other forms of arthritis.

Mean grip strength was $84.8 \mathrm{~mm} \mathrm{Hg}$ in the left hand and 84.5 $\mathrm{mm} \mathrm{Hg}$ in the right on first reading, 85.9 in the left hand and 87.0 in the right on second reading, and 86.9 in the left hand and 87.0 in the right on third reading. In their homes, 70 patients opened their own containers; 29 did not. The right hand was considered dominant by 91 patients and the left hand by six; two patients were uncertain. Ninety nine patients had arthritis in the left hand and 98 in the right hand. The mean duration of arthritis was 14.6 years and the mean duration of arthritis in the hand was 10.9 years. In some patients there was probably more than a single rheumatic diagnosis. The two hands were affected almost equally throughout the population. In only a few patients were the wrists unaffected. When there was arthritis in the elbows and shoulders this was usually symmetrical and left and right sides were affected equally in the population.

Table II shows the performance of the 12 containers on 12 of the most important questions asked of patients. In each case the results are graded from best (grade 1) to worst (grade 12). Where containers performed equally well, each is denoted as ranking at the mid-point of the group. It will be seen that container 11 performed exceptionally well and was selected a clear first choice in seven of 12 attributes and first equal in an eighth (fig 2). The only other containers ranking first choice were container 7 (first once and first equal twice) and container 8 (first once and first equal once). Moreover, container 11 ranked first in the patients' overall opinion (column 12).

There was little to choose between containers for time taken to open, though container 11 took less time than the others (table III).

Table IV shows the number of occasions on which containers were selected as best or worst. Container 11 again was the most popular and was never rated as the least satisfactory.

TABLE I-Details of 12 containers tested

\begin{tabular}{llrl}
\hline $\begin{array}{l}\text { Container } \\
\text { No }\end{array}$ & Manufacturer, drug & $\begin{array}{c}\text { Pack } \\
\text { size }\end{array}$ & $\begin{array}{l}\text { Medication } \\
\text { contained }\end{array}$ \\
\hline 1 & MSD, sulindac & 100 & $100 \mathrm{mg}$ tablets \\
2 & M\&B, ketoprofen & 100 & $50 \mathrm{mg}$ capsules \\
3 & Winthrop, benorylate & 100 & $750 \mathrm{mg}$ tablets \\
$4^{*}$ & Cassenne, tiaprofenic acid & 100 & $200 \mathrm{mg}$ tablets \\
5 & Syntex, naproxen & 60 & $250 \mathrm{mg}$ tablets \\
6 & Parke Davis, mefenamic acid & 50 & $300 \mathrm{mg}$ tablets \\
7 & Lilly, benoxaprofen & 60 & $300 \mathrm{mg}$ tablets \\
8 & Pfizer, prioxicam & 60 & $10 \mathrm{mg}$ capsules \\
$9^{*}$ & Cassenne, tiaprofenic acid & 100 & $200 \mathrm{mg}$ tablets \\
10 & Boots, ibuprofen & 100 & $400 \mathrm{mg}$ tablets \\
11 & Dista, fenoprofen & 100 & $300 \mathrm{mg}$ tablets \\
12 & MSD, indomethacin (slow release) & 100 & $75 \mathrm{mg}$ capsules \\
\hline
\end{tabular}

*Experimental design: not in current commercial use.
Thus container 11 was judged outstanding in almost all respects. Containers 4, 6, 7, and 8, however, appeared rather more satisfactory than the others and may be preferred by certain patients (fig 3 ).

\section{Discussion}

As the deformity that may occur in rheumatic hands varies widely, there is unlikely to be a single design of container that achieves absolute approval over all others. Nevertheless, trends emerge, and the inadequacy of blister packs has been the subject of previous studies. Of the existing containers, "flip top" openings proved difficult for most patients with arthritis, partly because of the force required and partly because of the small surface area on which that force has to be applied. Screw top containers are preferred, but tops requiring a large number of

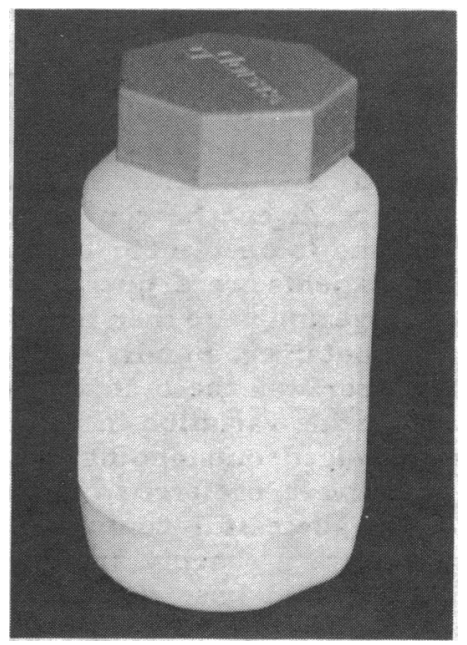

FIG 2-The container judged to be most consistently successful.
TABLE III-Time taken to open container, take out two tablets, and re close container

\begin{tabular}{|c|c|c|}
\hline Container No & Mean (s) & SD \\
\hline $\begin{array}{r}1 \\
2 \\
3 \\
4 \\
5 \\
6 \\
7 \\
8 \\
9 \\
10 \\
11 \\
12\end{array}$ & $\begin{array}{l}12 \cdot 6 \\
11 \cdot 8 \\
12 \cdot 8 \\
14 \cdot 1 \\
14 \cdot 3 \\
13 \cdot 5 \\
11 \cdot 7 \\
12 \cdot 2 \\
15 \cdot 4 \\
14 \cdot 1 \\
11 \cdot 2 \\
13 \cdot 0\end{array}$ & $\begin{array}{l}4 \cdot 9 \\
3 \cdot 2 \\
6 \cdot 1 \\
4 \cdot 9 \\
6 \cdot 4 \\
5 \cdot 6 \\
5 \cdot 5 \\
4 \cdot 4 \\
5 \cdot 9 \\
5 \cdot 2 \\
4 \cdot 4 \\
5 \cdot 6\end{array}$ \\
\hline
\end{tabular}

TABLE IV-No of times each container was voted "best" or "worst"

\begin{tabular}{ccc}
\hline Container No & Best & Worst \\
\hline 1 & 0 & 15 \\
2 & 0 & 28 \\
3 & 2 & 11 \\
4 & 15 & 1 \\
5 & 1 & 4 \\
6 & 22 & 1 \\
7 & 1 & 2 \\
8 & 5 & 0 \\
9 & 17 & 11 \\
10 & 4 & 5 \\
11 & 32 & 0 \\
12 & 0 & 21
\end{tabular}

TABLE II-Ranking of containers: results of questions asked of patients and graded from best (grade 1) to worst (grade 12)*

\begin{tabular}{|c|c|c|c|c|c|c|c|c|c|c|c|c|c|}
\hline \multirow{2}{*}{$\begin{array}{l}\text { Container } \\
\text { No }\end{array}$} & \multirow{2}{*}{ Drug } & \multicolumn{2}{|c|}{ Opening container } & \multicolumn{2}{|c|}{ Removing tablet } & \multicolumn{3}{|c|}{ Reclosing container } & \multicolumn{2}{|c|}{ Body } & \multicolumn{2}{|c|}{ Closure } & \multirow[b]{2}{*}{$\begin{array}{l}\text { Overall } \\
\text { opinion }\end{array}$} \\
\hline & & Ease & Pain & Ease & Pain & Ease & Pain & $\begin{array}{c}\text { Tablet } \\
\text { dropped }\end{array}$ & Size & Shape & Size & Shape & \\
\hline \multirow{10}{*}{$\begin{array}{r}1 \\
2 \\
3 \\
4 \\
5 \\
6 \\
7 \\
8 \\
9 \\
10 \\
11 \\
12\end{array}$} & \multirow{10}{*}{$\begin{array}{l}\text { Sulindac } \\
\text { Ketoprofen } \\
\text { Benorylate } \\
\text { Tiaprofenic acid } \\
\text { Naproxen } \\
\text { Mefanamic acid } \\
\text { Benoxaprofen } \\
\text { Piroxicam } \\
\text { Tiaprofenic acid } \\
\text { Ibuprofen } \\
\text { Fenoprofen } \\
\text { Indomethacin } \\
\text { (slow release) }\end{array}$} & 9 & 10 & 9 & 10 & 11 & 12 & 11 & 9 & 8 & 10 & 10 & 10 \\
\hline & & 12 & 11 & 4 & 2 & 10 & 10 & 2.5 & 6 & $9 \cdot 5$ & 12 & 12 & 12 \\
\hline & & $\begin{array}{l}8 \\
3\end{array}$ & $\begin{array}{l}7 \\
2 \cdot 5\end{array}$ & $\begin{array}{r}8 \\
10\end{array}$ & 12 & $\begin{array}{l}4.5 \\
6.5\end{array}$ & $\begin{array}{l}4.5 \\
4.5\end{array}$ & 12 & 12 & $\begin{array}{r}12 \\
5\end{array}$ & 6 & 7.5 & $\begin{array}{l}9 \\
4\end{array}$ \\
\hline & & 7 & 8 & 2.5 & $\begin{array}{r}10 \\
8\end{array}$ & 6.5 & 8 & 5 & 11 & 7 & $\begin{array}{l}\mathbf{4} \\
7.5\end{array}$ & 8 & $\begin{array}{l}\mathbf{4} \\
\mathbf{7}\end{array}$ \\
\hline & & 3 & $5 \cdot 5$ & 5 & $5 \cdot 5$ & 4.5 & 6 & 9 & 2 & 2 & 5 & $4 \cdot 5$ & 2 \\
\hline & & $\begin{array}{l}6 \\
3\end{array}$ & $\begin{array}{l}5 \cdot 5 \\
2 \cdot 5\end{array}$ & $\begin{array}{l}6 \\
7\end{array}$ & $5 \cdot 5$ & $1 \cdot 5$ & 1.5 & $\begin{array}{l}1 \\
7\end{array}$ & $\begin{array}{l}7 \\
4\end{array}$ & $\begin{array}{l}3 \\
5\end{array}$ & 3 & 3 & $\begin{array}{l}5 \\
3\end{array}$ \\
\hline & & 5 & 4 & 12 & 10 & 8 & 7 & 5 & 10 & 11 & $7 \cdot 5$ & 6 & $\begin{array}{l}3 \\
6\end{array}$ \\
\hline & & 10 & 9 & 2.5 & 2 & 9 & 9 & 9 & 8 & 9.5 & 9 & 9 & 8 \\
\hline & & 1 & 1 & 1 & $5 \cdot 5$ & 1.5 & 3 & 5 & 1 & 1 & 2 & 1 & 1 \\
\hline & & 11 & 12 & 11 & 5.5 & 12 & 11 & 9 & 5 & 5 & 11 & 11 & 11 \\
\hline
\end{tabular}

*Where containers performed equally well each is denoted as ranking at the mid-point of the group. 


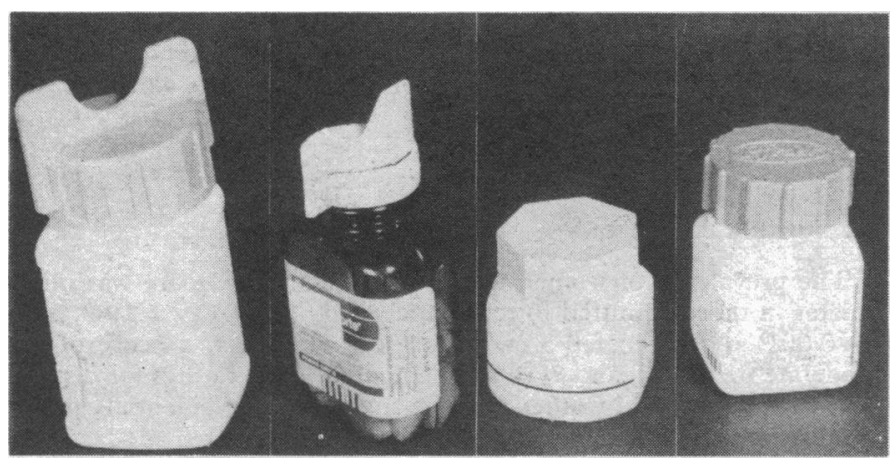

FIG 3-Though not so consistently successful as container 11, these four containers were judged more successful than the others.

turns (long thread) performed poorly in this study. The most successful containers had tall bases and angulated tops. The top should not be the same size as the base (preferably slightly smaller) and the base should fit comfortably in the hand. Glass is not liked by patients.

The best container was about $8 \mathrm{~cm}$ high with a lightweight base that had sides that were both flat and rounded (fig 2). The screw top should be deep and angulated or ridged with a very short thread.

It was interesting that one particular container proved outstanding in so many (but not all) respects. Though this was the only one of the 12 tested with an orange top we think it unlikely that the colour caused its success; colour has, however, been recorded as a reason for patients preferring tablets, red performing better than white. ${ }^{1}$ Of the four other containers that were more successful than the others two had wing tops; these appear to be a successful feature for some patients, though we admit to slight anxiety that the sharp edges may produce local injury in patients with fragile skin.

Two of the containers tested (No 4 and 9) were of experimental design and were not then commercially available. Container 4 has now been subjected to further modification and this version, claimed to have an improved performance, is now commercially available. Nevertheless, we urge those manufacturers whose products performed badly in this study to at least consider redesigning their containers in a similar style to one of those that performed better. It must also be understood that "childproof" is "arthritic proof" and society must distinguish between ensuring easy access to medicines for those needing them and parental responsibility in ensuring that this does not mean easy access for young children.

We thank Professor N S Kirk and staff in the department of consumer ergonomics at Loughborough University for performing the computer analysis; Mrs R H Schofield for typing the script; and Cassenne Ltd and Roche Products Ltd for financial support.

\section{References}

${ }^{1}$ Wright V, Hopkins R. Administration of anti-rheumatic drugs. Ann Rheum Dis 1976;35:174-6.

2 Mason DIR, Brooks PM, Maurikakis ME. Study of opening medicine bottles in patients with rheumatoid arthritis. fournal of Clinical and Hospital Pharmacy 1976;1:171-5.

${ }^{3}$ Lambert J, Hopkins R, Wright V, Cardoe N. Child restraint containers: an appraisal in arthritic patients. Rheumatol Rehabil 1978;17:89-91.

\begin{abstract}
The increasing number of people aged over 75 in Britain makes heavy demands on health and social services. To obtain accurate information for rational allocation of resources to domiciliary and residential services a group of 98 housebound women over 75 were compared with a group of 99 women of the same age in residential care. They had a similar range of physical disorders with the exception that deafness was more common among women in residential care. A much higher proportion in residential care were demented. Though in many respects women in residential care had less physical incapacity, a
\end{abstract}

Department of Medicine, University of Dundee, Ninewells Hospital and Medical School, Dundee

W J MACLENNAN, MD, FRCP, senior lecturer

Dundee District Health Board, Westgate Health Centre, Dundee

F E ISLES, MB, CHB, senior clinical medical officer

$S$ MCDOUGALL, MB, CHB, senior clinical medical officer

E KEDDIE, NNEB, RGN, community nurse

Correspondence to: $\operatorname{Dr}$ J MacLennan. higher proportion needed help at times of crisis. Important social factors were that women at home were more likely to be living with others, and that the principal helper was more likely to be a husband or relative than a neighbour. Both groups received the same amount of support from home helps and community nurses.

Any reduction in the number of residential care places for elderly women whose relatives are not available or are unable to cope would require the establishment of an effective community psychogeriatric service and a system for providing appropriate subjects with 24 hour care and supervision.

\section{Introduction}

In Great Britain the number of people over 75 continues to rise, and as many suffer from mental or physical incapacity they make heavy demands on health and social services. ${ }^{12}$ One form of support is residential care, but this is expensive and exposes clients to the disadvantages of institutionalisation. ${ }^{3}$ An alternative is to use domiciliary services to maintain old people in their own homes. Such services, however, are also expensive, and while appropriate for people requiring periodic intervention, are less effective in those requiring constant attendance. ${ }^{45}$ 